\title{
Application of Engagement Theory in the Literary Education
}

\author{
Chuanbo Huang \\ Dezhou University, Shandong, China \\ Email: hcbdzxy@126.com
}

\begin{abstract}
Though Engagement Theory is a result of long-range educational practice, it is also applicable to our university literary education because current students are inclined to network association instead of reality. Engagement Theory emphasizes cooperation, creativity and contribution, which can settle network crisis around universities and have enormous advantages in the literary aesthetic education. When we apply the theory, it should be made scientific, effective and humane.
\end{abstract}

Index Terms -Engagement Theory, literature class, education, cooperation

Present university students have tremendous difference with traditional university student. They attach importance to utility value and ignore quality. They study for the material gain but not for humanism. A lot of students study hardy in order to take the credit, deal with the examination, obtain degree, and even graduate students seldom think over making any knowledge. As is even more relevant, present university structure of education are more utilitarian. Humane quality course have been generally compressed at the lessons. The contradiction between being expanded content of courses and reducing lessons day by day is very sharp. Meanwhile, many people point out that students need strengthen humane quality urgently in the situation that market economy is highly praised. In humane quality courses of university, literary aesthetical education has a very important role. Lu Jingchao once mentioned that BaJin told her daughter that the literature masterpiece could educate us, encourage us, and make us become better, more pure, more kindhearted, more useful to others, and the purpose of literature is to make people become well. But present university students, even those majored in literal arts, lack adequate awareness of the enormous potentiality that profound cultural deposits can mould the wholesome personality. Facing the choices between the ability of literary reinterpretations and foreign language or computer grade certificate, they are willing to get the latter. The current situation has cause a lot of anxiety of literature educator, many of whom are thinking about the solution actively. They make great efforts to use many kinds of education skill means to lead students to pay close attention to literature, and face the cultivation of the aesthetic educational quality of literature.

The research of Cognitive Learning Theory shows, while studying and training advanced cognitive ability, traditional receiving type, the specific type teaching way is not effective. So, coordination and exploration in study have become the focus that people pay close attention to. In this respect, Engagement Theory can give our literature educator beneficial reference.

\section{ENGAGEMENT THEORY'S PROPOSITION AND IDEAS}

Engagement Theory is a kind of study theory that U.S.A. educates technologist, Karsley and Shneiderm, put forward in their long-range educational practice for many years. Though it is a result of long-range educational practice, it is also applicable to our university teaching. Because of the restrictions of present university course system, the content that students really learn in the classroom is far from adapting to the development of the present social situation. The development of the modern network makes it already become a part of people's life at the same time, and broad network resource let teacher, classmate benefit a great deal already. A lot of students spend a lot of time on network especially. So, Engagement Theory can aide our present university classroom instruction effectively. Its premise is that the learner will not produce effectiveness unless throw themselves into the study. The development of these studying activities depends on the interaction between learner and others, and accomplish valuable task at the same time. The basic idea of Engagement Theory is to establish successful cooperation group in the non-traditional teaching environment, and enable its study based on that certain task be carried on meaningfully

Karsley thinks that Engagement Theory has three basic principles: relate, create and donate. Relate principle, emphasize that learners contact and trust each other. Drawing support from colony, they communicate with others, obtain help and finish the tasks they wanted to accomplish themselves in cooperating. In return, they must help others solve problems and make progress together. Cooperation and exchange can make students solve the human resources problem effectively, enable some creative activities needing lots of human resources to go on, and strengthen the continuation of study at the same time. Because of the differences, such as IQ, knowledge, mode of thinking, among students, it will be doomed to be diversified on study ways in cooperation, which can make everybody learn from other's strong points to offset his weaknesses and the knowledge structure is improved, rational further. Create principle 
regard studying as a kind of activity that has innovative value. The society has already entered information age at present, and the things in daily life change with each passing day. In such a case, innovation is particularly important. This principle often expresses through "Problem Based Learning" in Engagement Theory. Einstein said: "Propose a problem is often more important than a problem of solving, because it is perhaps only a scientific experiment skill to solve a problem. And put forward the new question, new possibility, and the old problem from the new viewpoint, but need creative imagination, and mark scientific real progress. Because of the existence studying group, one's own question can be proposed, so the students may face more questions unexpected. Through studying together in the face of these questions, they must get tactics and method to solve problem by researching various study means in the course of solving the problems, which not only can help students to solve problems, but also train students to obtain knowledge and meaning and build the ability to construct knowledge. Donate principle, make the learner's study not only meet personal society need, but also make some contribution to others and the world, which really improved one's own humane quality at the same time. Present students are more practical in study, so there are more choices of their question is on social value and meaning aspect. Undoubtedly it helps our society work normally and is favorable to university student's personality at the same time.

Meanwhile, a lot of universities face an awkward situation instantly, which is the conflict between the ordered teaching on the universities and the ever-increasing, disordered internet bars outside the campus. not solving the university. In the face of the students indulging in the network game, many educators and patriarchs feel helpless mostly after condemning it. Instead of saying no to internet bar absolutely, we should utilize it. As to the net surfing behavior of university students, we should carry on the guide of enthusiasm, and fully utilize the existence of the internet bar. Through investigation, we find that many university students spoiling in the internet result from that they have nothing to do and wonder what they need on the net. Engagement Theory encourages study in cooperative type, which can make student receive happiness of study among network, and thus solve the harmful effects of internet bars to the teaching environment of the university effectively.

\section{ENGAGEMENT THEORY'S ENORMOUS ADVANTAGES IN THE LITERARY AESTHETIC EDUCATION}

Literary aesthetic education concerning human ultimate value is one undertaking of unreality. Under the present practical condition in the society, we especially need to hold one's ground on aesthetic and spirit value. During the process, Engagement Theory has enormous advantages.

A. The Information Capacity of Literature Courses is Large, and its Density is Thick, Which is Favorable to the Expansion of Students' Visual Field

The mankind has the civilized histories of several thousand years, possess a lot of precious cultural heritage, and have long historical cultural traditions. Nowadays is a information-intensive society instantly, and peoples are in an era of big explosion of and knowledge information. It is the literary works that reflect such social life. It reproduces various scenes in natural and social life truly, reflects the economy, politics and culture idea of certain historical period. It also reflects the prevailing custom of the society and social culture and ideology for each historical stages. In the present university education system, the development of literature courses is more perfect day by day. Foreign language literature and Chinese language literature have their own sub discipline. Take, for example, Chinese language literature, has been divided into Chinese classic literature, Chinese modern Literature, Chinese contemporary literature, foreign literature etc. It is impossible for students to accept and understand so vast and numerous literature content, and it is a impossible task only through classroom teaching. The literary works that each student has read and understood are different. Their attentions are different. The teacher can use Engagement Theory to organize students to carry on the discussion on some special topics. Different students finish different points of tasks, which resolve the difficult problem that individuals can't read too many works. Then they exchange in everybody's cooperative course relevantly. Undoubtedly it increases the information capacity that students accept and expand their visual field.

\section{B. Students' Ways of Participating Studying have the Characteristic of Diversification and Combination, Which have} Accelerated the Rhythm of Teaching

Because students' modes of thinking are different, their considering method has very great differences. In the cooperative course, discussion helps learners to make use of sight and hearing at the same time and experience information omni-directionally. Under the popularization of modern education skill, collective strength will make the study of the concrete problem become simple figure, picture, chart, cartoon, sound result, background music become one flesh. The teaching means is with excellent pictures and texts, and sound and shape concurs. It is up to and the cognitive rule and learning laws of the students, and can further stimulate students' study interest, accelerate teaching rhythm in order to meet present literature course reform. Though teaching finishes in the classroom, Engagement Theory will make much study of students' to finish outside the classroom. To meet the request of participating study, the classmates can be easier with exposed to the each aspect of society conveniently in Internet, download all kinds of works, and participate in the forum activity besides one's own reading the text personally. It makes their visual field widen further and thinking is more active.

\section{Strengthen Cooperation and Identify with the Community}


Relate principle emphasizes the skills correlated with cooperating of mutuality, management, evaluation, plan etc. It has promoted treatment of student's interpersonal relationships. With the constant development of market economy, the change has taken place greatly in people's outlook on life, values. To many people, the modern interpersonal relationships are win-win relations. The relationship cannot maintain long-term unless both sides have benefit. That is, there is no eternal friend, no eternal enemy, and only eternal interests. This idea will aggravate the modern feeling of loneliness, and make people break away from the colony, unable to communicate with people normally. It is very dangerous to the young students who will come upon the stage. Engagement Theory emphasizes cooperation and mutuality. It is the cooperation in a group. Everybody will realize collective strength in cooperation. The group maintains by spirit, and everybody trusts and interdepends each other. They study together, practice together, share experience and achievement, which will form a kind of social responsibility and collective sense of ownership and acceptance. Meanwhile, the existence of social acceptance will promote the mutual cooperation among people, and these two respects were proposed and complemented each other.

\section{Accepting Literary Aesthetic Education by Participating can Deal with Post-modern Context of Culture.}

In middle and later periods of 1990 times, post-modernism entered China in whoopla. It gives up completely responsibility of enlightenment and idealism, which make its literature text totally turn into the desire expression of materialism. The entanglements of individual ego consciousness and subconsciousness make modern's soul current situation register as inhibited, frightened, boring, fantastic and impatient. The metaphysics spirit of surviving is discarded. Post-modern context of culture has caused negative influence to the contemporary young man. It has caused their discontent to literary world instantly, even resist. The attitude is not only unfavorable to the normal development of literature, but also unfavorable to the completion of their outlook on life. In fact, a lot of young men love literature. Engagement Theory can deal with this kind of contradiction in teaching. When we carry on literary aesthetic education to students, we should require them to read literary texts at first. Through reading texts, they can improve the ability of beauty appreciation, form controversy in cooperate and mutuality, and realize the glamour of the literature texts in cooperative analysis.

\section{TAKE Note OF Following PRINCIPLES OF APPLYING ENGAGEMENT THEORY IN LiTERARY AESTHETIC EDUCATION}

\section{A. Scientific Principle}

The purposes of using Engagement Theory in literary aesthetic education include the research of applying many teaching tactics, optimizing the goal of study and improving teaching benefit, not only in order to tell students the content of the literary works. We must live up to scientificity on the exertion and operating of discussing ways. According to different content of courses, teaching goal, we should choose the mutual cooperative way suitable most in different focal points and difficult point, and not let students participate only. The organization of students should strive to be keeping to the point, the focal point is clearly demarcated, and the difficult point is outstanding. We should put improving student's humane quality and creativity in the first place.

\section{B. Effective Principle}

Under the environment of teaching of modern education skill, students may utilize many kinds of media way in participating in teaching. The media are only the tool and means to transmit teaching information. The intelligent use of media's could achieve the goal of improving student's aesthetic quality. Therefore in actual teaching, we must avoid to join in the fun, pursue garish, make literary texts turn into winsome new things, and throw student pursue sense organ. Therefore adhering to the principle of obeying the result in form, we optimize the training course of listening, speaking, reading and writing, make great efforts to unleash students' dynamic role and creativity to the maximum extent, and make students really realize the glamour of literature.

\section{Humanity Principle}

Making students participate in studying, might not make some overly inflexible subjects and questions for students only in order to accomplish the task of teaching. We should create a loose, active study atmosphere for students, enable them to focus on study. We should let them reach the deep layer of the content of courses conscientiously, activate their thinking inspiration constantly, and stimulate their thinking desire. Thus, they would feel it is anything happy and light that literature course is studied. The course teaching of literature reflects the humanized characteristic, which will not deviate from the human-oriented educational objective.

\section{REFERENCES}

[1] Sun Di. (2005). On the enlightenment of engaged learning theory to construct virtual learning community. Distance Education Journal 6, 21-25.

[2] Liu Fan-feng. (2002).The new teaching model based on technology: engagement theory. Studies In Foreign Education 8,7-9.

[3] Kearsley \& BenShneiderman. Engagement Theory: a framework for technology-based teaching and learning. http://home.sprynet.com/ gkearsley/engage.htm (accessed 4/5/1999).

[4] Lu Jingchao. A story between BaJin and a child. http://bbs.pep.com.cn/thread-26818-1-1.html (accessed 27/8/2002). 
[5] Huang Fa-you. (2007). The means of love knot in literary education. Journal of Tianjin Normal University 1, 52-58.

[6] Qian Li-qun. (1999). Recast the soul of scholar. Shanghai: Wenhui publishing house.

Chuanbo Huang was born in Dezhou, China in 1976. He received his M.A. degree in Chinese modern literature from Nanjing University, China in 2003.

He is currently a lecturer in Dezhou University, Dezhou, China. His research interests include Chinese modern and contemporary literature and culture.

Mr. Huang is a member of Research Academy of Modern Chinese Literature. 